\title{
Comentario
}

\section{La generación de las identidades}

Alfredo Cardona Tobón *

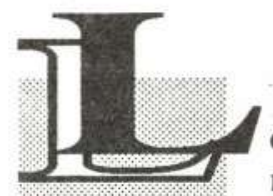

os derroteros de las naciones están marcados por generaciones con decisión para formar un camino, con objetivos definidos y una causa que aglutine a quienes tienen el poder de izar el velamen del destino.

Algunas generaciones determinan el rumbo de las comunidades. $\mathrm{Al}$ revisar el pasado vemos las generaciones del «destino manifiesto» norteamericano empinándose desde el Océano Atlántico para atar a su patria a la inmensidad del Océano Pacífico, o las generaciones victorianas de Inglaterra cuyo orgullo imperial dió fuerzas a su país para permanecer, pese a los vaivenes, en la primera línea de las naciones.

Da grima adentrarnos en nuestra historia ... allí sólo vemos sucesivas catervas neronianas encendiendo jubilosas la hoguera de la destrucción y a grupos rabiosos enrolando a millares de conciudadanos en la danza interminable de la violencia colombiana.

Cuando Rincón marcó el gol contra Alemania o nuestro seleccionado cerró la bocaza de Diego Maradona con el marcador de cinco a cero, los colombianos vibramos al unísono. Algo sublime nos unió en esos instantes. Por algunas horas sentimos esa identidad esquiva durante tantos siglos. En ese momento el bandido experto en minas «quiebrapatas» y el defraudador del Estado

\author{
«Sólo le pido a Dios que la \\ historia no me seaindiferente»
}

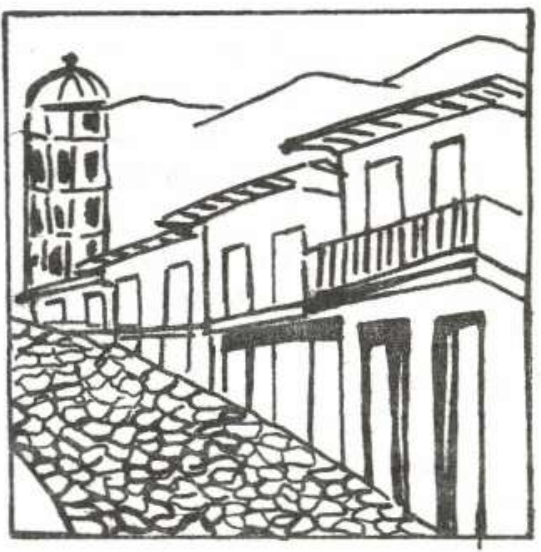

* Ingeniero, humanista, escritor. Docente de la Facultad de Ingeniería de Sistemas, Universidad Autónoma. Autor de varias publicaciones como: Ruanas y bayonetas (1988), Quinchía mestizo (1989), y artículos en la revista del Centro de Investigaciones históricas Registros de la historia, tales como « Las guerras civiles en Riosucio» (1987), «Sucesos de Manizales y sur de Antioquia» y «Colonización y poblamiento de Belalcázar» (1988), «Poblamiento del municipio de Guática» y «La comunidad de Quinchía» (1989), «Biografía mínima de Clemente Diaz Morkums (1990). 
comulgaron con el maestro perdidoen la escuelita cordillerana unidos por un símbolo ... y sobre todo por un sentimiento de pertenencia a la patria.

El día que Colombia sea para nosotros más que un territorio y se identifique con el pasado, con el presente y con nuestros sueños, perdurará ese sentimiento de pertenencia y se vislumbrará un futuro común. Quizás estén llegando las generaciones comprometidas con Colombia, pero tendrán que recorrer caminos empinados: deberán superar la etapa comarcana y rebajar ese egoismo superlativo que constituye uno de los grandes antivalores latinoamericanos.

\section{Un pasado brumoso}

La prospectiva parte de tendencias, estudia las causas y las circunstancias para explicar los sucesos actuales y dirigir las comunidades hacia un destino claro. No se apoya únicamente en teorías económicas, se vale de la historia y tiene en la cultura un aliado para abrir brechas y señalar caminos.

No basta la tecnología, ni lacivilización, ni siquiera la riqueza para hacer feliz a un pueblo. Se necesita la justicia, la igualdad y el respeto al hombre enmarcados en una cultura de comprensión y tolerancia.

Tendrá nuestra cultura los elementos necesarios para elevar al pueblo colombiano? No creo.

Se habla de viejos valores. Qué valores debemos reencontrar para retomar un sendero ?

En el país jamás se respetó la vida ni el derecho y ha sido el dinero la meta final de todos los esfuerzos.

Digamos, en cambio, que es necesario inculcar los valores cristianos que hemos pisoteado.
Nuestra sociedad está más y más desorientada. Quizás un segmento de la clase media es la que ha impedido que esto se desmorone como Sodoma y Gomorra. Esa clase media actuando en asociaciones de todo tipo, en las universidades, las escuelas, el periodismo, la Iglesia ... ha evitado que nos sumerjamos en un vórtice de fuego al sostener precariamente los principios del deber, la familia y el honor.

\section{La Generación de las identidades}

Un grupo heterogéneo compuesto por profesionales de varias disciplinas está tratando de reconstruir el pasado y palpar el alma de esta región. Su afán está señalando varias inquietudes: Unos pretenden dar fe de los sucesos, otros se recrean con las costumbres, el folclor y los sentimientos populares y algunos se sumergen en el corazón de las comunidades tratando de hallar las razones de nuestros desequilibrios, éxitos y frustraciones. Este grupo bautizadopor el doctor Ottro Morales Benítez como la «Generación de las identidades» reune cuarentones y cincuentones cuyo denominador común es el desencanto.

Esta «Generación de las identidades» no cuenta con figuras fulgurantes, ni tiene en sus filas mesías ni mariscales. Pero su trabajo retumba como el de los hacheros en la soledad de los montes. Su labor es contínua, incansable, prolífica ...

Sin apoyo estatal, sin mecenas ni aplausos trabaja en todos los frentes de la cultura del Viejo Caldas. El licenciado Victor Zuluaga G. ha recuperado valiosa información de los resguardos indígenas; Eliécer Zapata B. se ha sumergido en las gestas mimeras y las negritudes; Albeiro Valencia LL. está enriqueciendo los estudios del poblamiento al analizarlos bajo prismas sociales y económicos; César Valencia T. levanta la voz de la provinciaen el «Encuentro de la palabra»; Julián Bueno G. 
revive el alma caucana dormida en las veredas del Alto Occidente.

En la «Generación de las identidades» se siente el deseo ferviente de análisis y autocrítica sin incienso nizahumerios. Posee una fuerzainterior manifiesta en publicaciones comolarevista «Papel Periódico» de Anserma, en «Supía Histórico» en "Registro de Historia» y las numerosas obras que auscultan el pasado y el presente de Pensilvania, Villamaría, Neira y Marquetalia ...

En cada zona existe una avanzada con sus francotiradores de la cultura: En Risaralda el Centro «Bernardo Arias Trujillo» y la polifacética familia de los Vélez Correa; en Supía el Centro «Simeón Santacoloma»; Danilo Calamata en Chinchiná, Rafael Vinasco T. con sus deliciosas crónicas de Riosucio; Alberto Gallego E. y Miguel Giraldo Rodas reviviendo los episodios legendarios de Marmato; Belisario Ramírez G. redescubriendo el periodismo de provincia y los trillados caminos de arriería.

Qué impulsa a este grupo heterogéneo y numeroso a repasar y escudriñar nuestras realidades?

Cada uno tiene su respuesta. Lo cierto es que unos y otros están encontrando razones y exponiendo tesis que la universidad, ya que no lo hace elEstado, debería constatar y recoger para que esta «Generación de las identidades» no vaya a quedar enclaustrada en los anaqueles particulares o en los registros pueblerinos de las Casas de la Cultura. Es un esfuerzo colectivo y serio que, quizás, es único en el limitado ambiente intelectual colombiano.

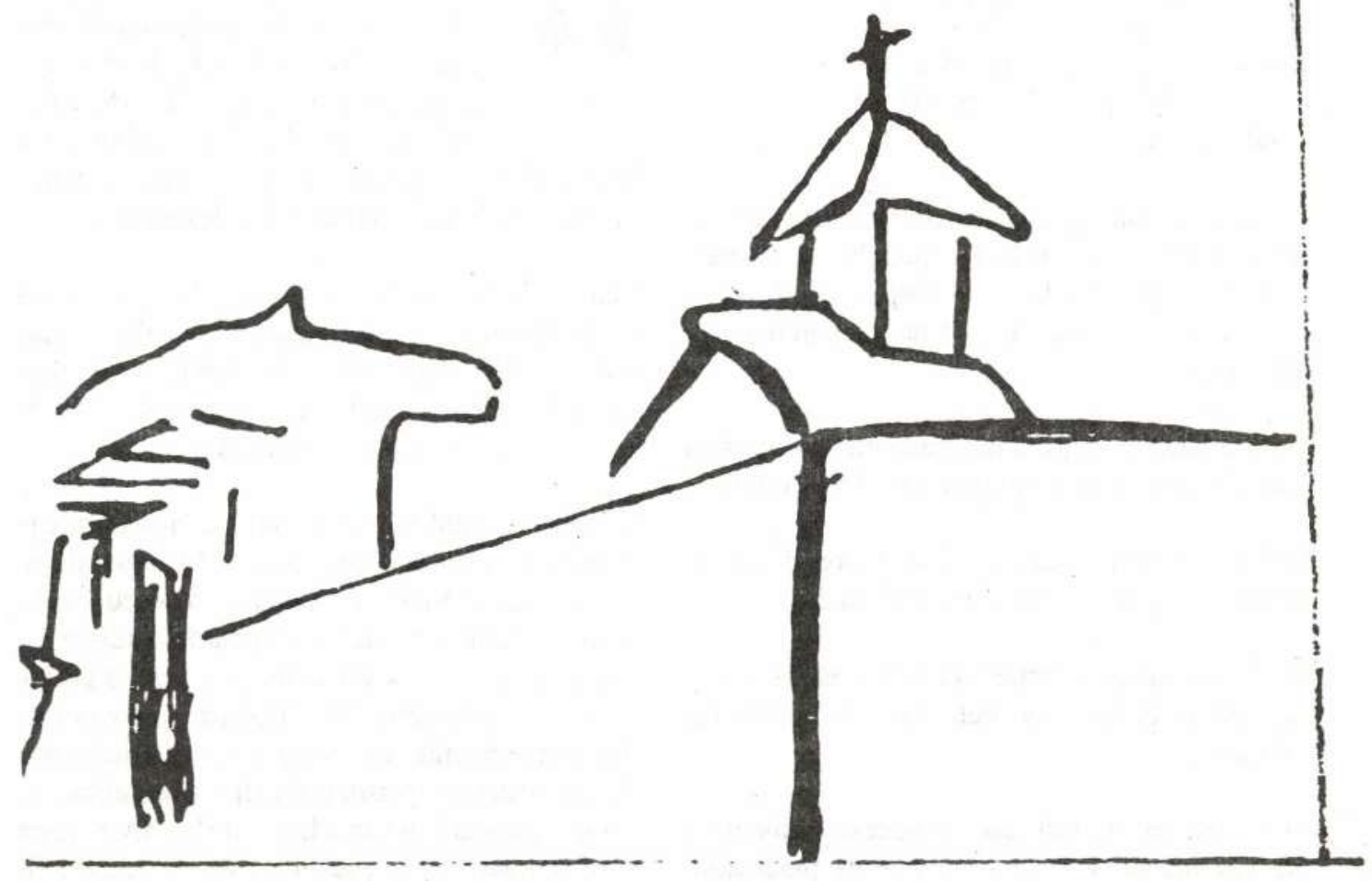

